\section{AN OPERATION FOR CYSTOCELE.}

BY W. P. GRAVES, W.D., BOSTON.

OF all the plastic operations on the vagina, the most difficult in which to attain a permanently successful result is that for cystocele. Numerous ingenious operations have been devised and exploited, but after all has been said, the perfect operation which in all cases can be relied upon has not yet been invented. However, many of the difficulties and disheartening results which attend the treatment of cystocele can be avoided if it be remembered that the anatomical conditions vary in different cases of cystocele, and that that operation must be chosen which shall best meet the requirements of the particular case.

The all-important essential in selecting the appropriate operation is the condition of the vaginal attachments to the pubic arch. The vagina depends for its support on these attachments, and if they are intact the deepest tears of the perineum or the vagina offer excellent promise of permanent cure provided that an operation be done which takes advantage of this support.

If, on the other hand, the vagina has broken away from the pubic arch, operations on the vaginal wall alone are of little use, and though relief may be given for a time, eventually partial or complete recurrence of the cystocele is almost always the rule. In these cases the uterus, which depends largely for its support on the vagina, prolapses, and adds its weight to that of the bladder and intestines to aggravate the condition of the cystocele. When loss of pubic support and prolapse occur, an operation on the anterior wall should usually be done, but only in connection with an operation which will support the vagina to some fixed point, as, for example, the anterior abdominal wall. By far the best operation for accomplishing this purpose is Dr. Baker's vaginapexy or Dr. Polk's colpo-orrhaphy.

The operation described in this article is purely an anterior colporrhaphy, and depends for its success on the presence of pubic attachments. It was first used by the writer to repair recurrent cystocele, and is now. used in cases of simple cystocele and in conjunction with vaginapexy. Its essential principle is, of course, that of any anterior denudation which seeks support from the sides, but has in addition the purpose of gathering up all the slack tissue so as to avoid protrusions and to leave the anterior wall perfectly smooth. It is these protrusions which often work mischief in the result of a cystocele operation, for they act first like a wedge to break down the important support given by a firmly repaired perineum, and, secondly, as starting points for a new cystocele, according to the principles of any beginning hernia. The most important protrusion to reduce is the somewhat loosely-called urethrocele. This consists usually of an hypertrophied tab of vaginal tissue, and in operations for perineorrhaphy should always be reduced even in cases where cystocele does not exist above it, as it is sure in time to stretch out the external portion of the repaired perineum.

No particular originality is claimed in this operation, as it combines and modifies principles long ago described by Dr. Emmet.

The steps of the operation are as follows: Two points are selected on each side of the cystocele, about one-half inch from the lateral creases, which, when drawn together (A to B and C to D), sufficiently reduce the cystocele and at the same time do not exert undue tension on the lateral flaps. With these four points as corners, a rectangle is then denuded. A point is next selected on the urethral tab $\mathrm{E}$, which, when drawn down . to the approximated points A and B, completely reduces the urethrocele. The tissue included between points $A, B, E, F$ and $G$, is denuded. $\mathrm{F}$ and $\mathrm{G}$ represent two deeply-set dimples, which are always present nearly on a level with the meatus.

The denudation of the angles $\mathrm{H}$ and $\mathrm{I}$, two points at the sides of the cervix, is made in order to take out the slack caused by the approximation of $C$ and D. It is not always necessary to denude these angles, and in such cases the denudation may be carried down to a point and the sides brought together as in the oval operation. This is shown in Fig. 3 by the dotted lines at the angle

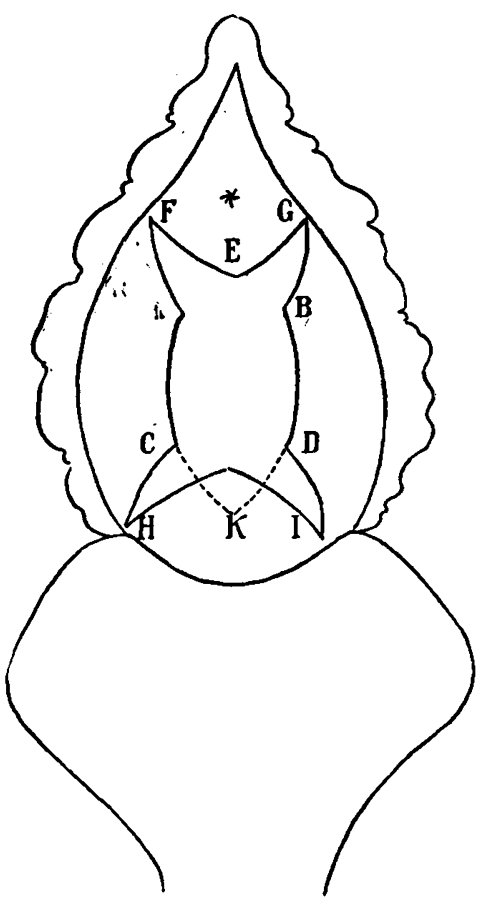

FrG. 3. - Diagram to explain Fig. 1.

$K$. This form of denudation is sometimes an important procedure, for it assists in carrying backward a cervix which has a tendency to prolapse.

Great care should be exercised in making the denuded figure symmetrical, so as to gain perfect approximation of the edges, for in all vaginal work it is the perfect approximation of the edges of the wound which avoids sepsis and secures union by first intention. 


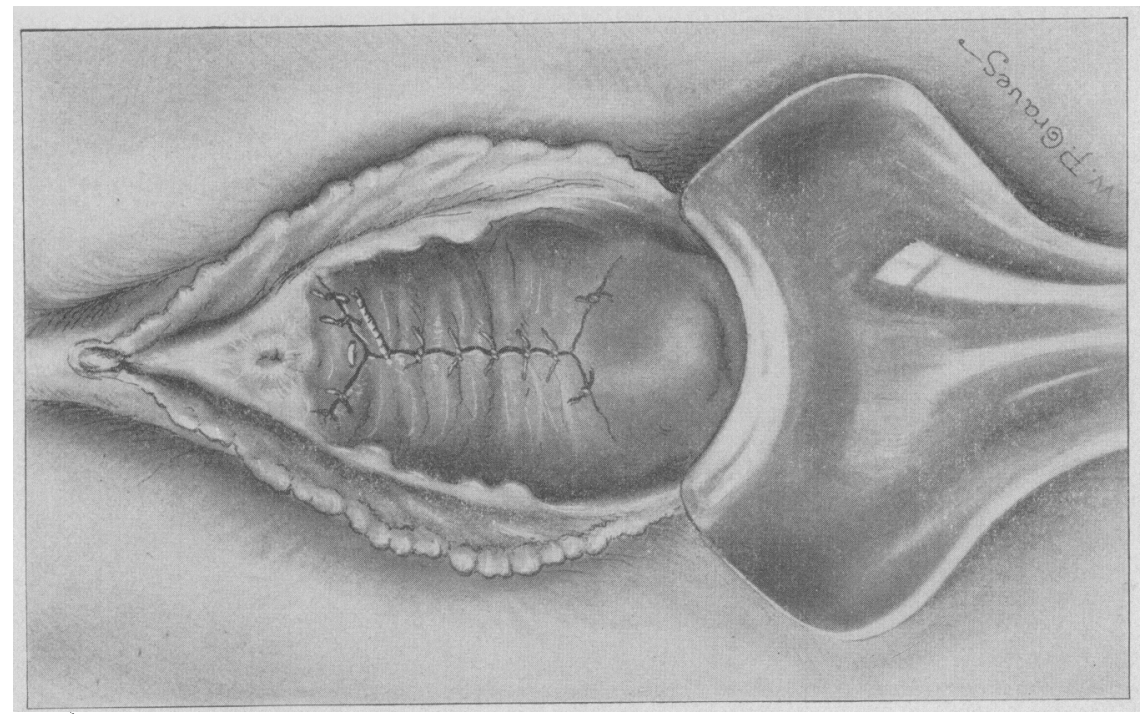

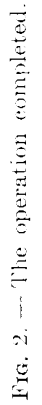

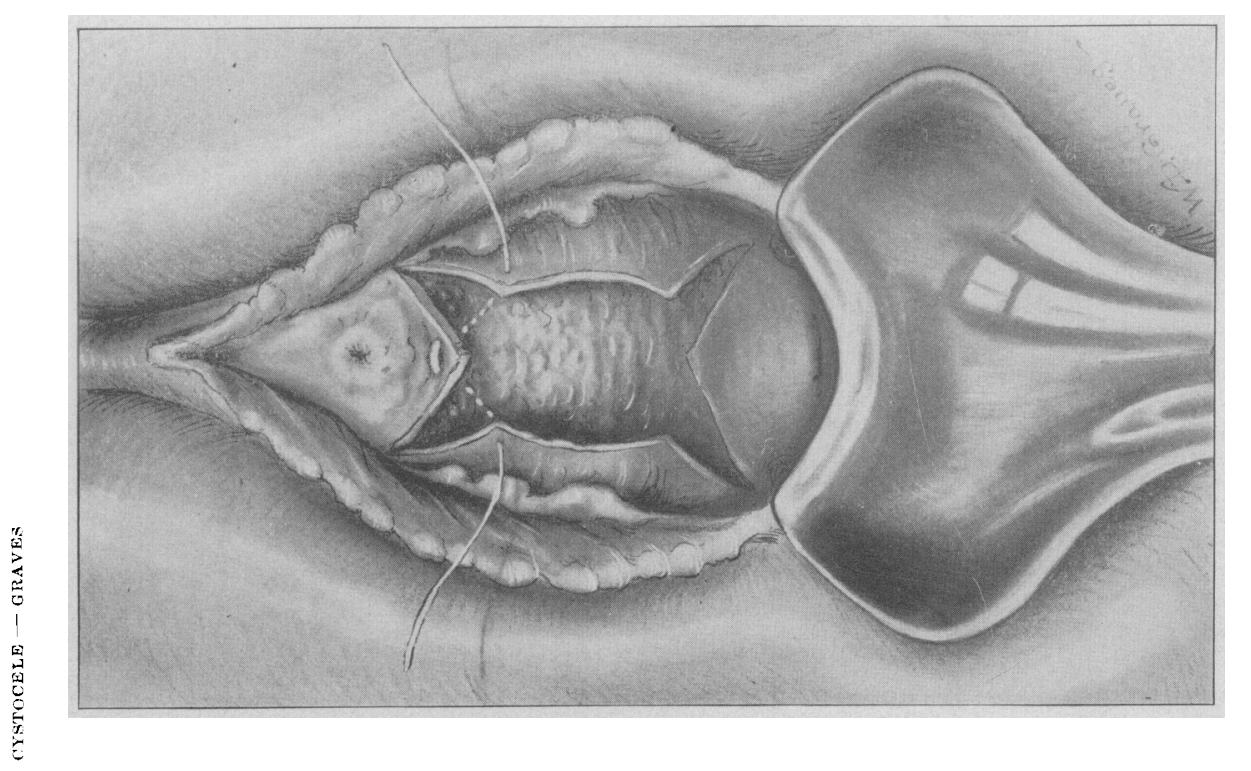

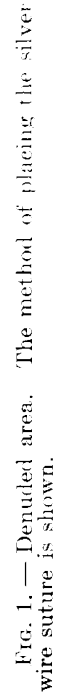

The Boston Medical and Surgical Journal as published by 
The wound should be closed with silkworm gut or chromicized catgut sutures, excepting at the point where $\mathrm{A}, \mathrm{B}$ and $\mathbf{E}$ meet. This is a crucial point for the avoidance of sepsis and non-union, and for that reason a silver wire suture is used. By placing it as depicted in Fig. 1, the corners can be fitted to a nicety without cutting off their circulation.

After finishing the operation for cystocele, $a$ perineorrhaphy should always be done, even in cases of recurrent cystocele where the perineum has been previously repaired. A firm perineum should be done and one which will hug closely the anterior wall. Stitches from the cystocele operation may be removed as soon as the perineum is strong enough to stand the traction of a speculum, usually about the third or fourth week. Daily corrosive douches should be administered, great care being exercised not to allow the corrosive solution to enter the urethra. The patient should be encouraged to pass her water as soon as possible, in order to avoid the continued used of the catheter.

\section{SOME INFLUENCE IN FAVOR OF BEITIER MARKET MILK.*}

BY R. A. PEarson, ithaca, N. Y.,

Professor of Dairy Industry, Cornell University.

In dairying, as in many other lines of industry, there is to-day a decided movement for improvement. This improvement is chiefly in the direction of more sanitary methods of producing and handling milk. Several different influences are responsible and I propose to mention and briefly discuss some of the chief ones.

I. Laws and ordinances. Most states have laws relating to milk and most cities have ordinances on this subject. These legal regulations usually prescribe standard or minimum amounts of fat and total solids. Three 3 per cent fat and 12 per cent total solids is the most common standard, but in Massachusetts the standard is a little higher. So far as this milk standard is concerned, the laws and ordinances are generally well enforced. It is easy to enforce such provisions because they are definitely stated and failure to comply with them may be easily proved. Legal regulations usually apply also to the sanitary conditions under which milk is produced and handled; these include the health of the cows, manner of stabling, character of feed, handling of the milk, etc. Obviously it is difficult to state requirements relating to these subjects as exactly as those relating to composition of milk, hence such requirements are not as well enforced. In fact, in many cases no attempt is made to enforce regulations other than those having to do with the composition of milk unless the most serious conditions exist. The great majority of dairies sending milk into our cities are never regularly inspected and conditions must become exceedingly bad before they are noticed.

It should be understood that well-meaning

* Paper read before the Suffolk County Medical Society, Boston, Mass., Dee. 20, 1905. dairymen do not object to but rather favor the enforcement of reasonable milk laws and ordinances as they see the advantage of preventing dishonest practices. Official records show that where reasonable regulations are enforced, the amount of milk used is large as compared with the amounts used in places having poor or poorly enforced laws. But the best dairymen would like to see milk regulations clearly stated and dignified by being separated from other municipal regulations relating to garbage, cemeteries, and like subjects and, more important, they would like to see these regulations enforced by men who have been trained to do such work and not those who are appointed merely because it is the wish of some politician. A dairy inspector who has been well-trained for such work may often accomplish more good by giving advice where it will be useful than by his detective and police work.

Furthermore, dairymen would heartily approve enactment of new laws that would relieve them of much trouble and loss and of much blame, now unjustly heaped upon them. These would include laws relating to the care of milk bottles and, more important, the condition of milk cans when returned by dealers to dairymen. And dairymen would welcome laws that would prevent dishonest competition, such as is seen when one dealer having poor milk succeeds in getting trade by making grossly inaceurate claims.

II. The second influence is public demand for purer milk. This is increasing slowly. If the public were anxious to get better milk than they are now getting they could have it very soon, but the fact is that the great majority is satisfied with the present milk supply. If the milk going into most houses contains a fair proportion of cream and will not sour in twenty-four hours it is quite certain to give satisfaction. The purchaser gives little or no thought to its condition otherwise than stated. Perhaps the average householder can be excused for this neglect on the grounds that she innocently believes the milk inspectors will protect her from unwholesome milk. But can we excuse the hospitals and other large institutions on the same grounds? Their position seems remarkable to say the least. These establishments are managed by men who know the real conditions, yet most of them buy their milk on contract with no stipulation whatever as to quality. It is, of course, understood that the milk shall shall be sweet and contain at least the legal standard of fat. Most consumers and dairymen will say if the ordinary milk is good enough for the patients in hospitals where there seems to be no lack of funds for expert treatment and wholesome food, then that same milk must be good enough for well people.

III. The milk commissions constitute the third important influence. These commissions have received much credit but not as much as they deserve. I believe the value of the commissions should be extended and they should receive support for their work from the public treasury. In the end they accomplish much that the regularly 